1 Therapeutic effects of continuous epidural infusion of local anesthetics with dexamethasone for

2

3

4

5

7

8

9 E-mail: Jung Eun Kim, M.D, Ph.D : geri200@gmail.com;

\section{postherpetic neuralgia} University College of Medicine, Seoul, Republic of Korea

Joo-Hyun Jun, MD, PhD : ilpleut@ naver.com

Eun Hee Chun, MD, PhD : ppodoll@hanmail.net

In-Jung Jun, MD,PhD : christine17@ hanmail.net

Jong Hee Park, MD : tomclaney@naver.com

Eun-Ha Choi MD : hello_13@naver.com
Eun Mi Choi, MD, PhD; Mi Hwa Chung, MD, PhD; Joo-Hyun Jun, MD, PhD; Eun Hee Chun, MD, PhD; In-Jung Jun, MD,PhD; Jong Hee Park, MD; Eun-Ha Choi MD; Jung Eun Kim, MD, PhD

Department of Anesthesiology and Pain Medicine, Kangnam Sacred Heart Hospital, Hallym

Eun Mi Choi, M.D, Ph.D : emchoi96@hallym.or.kr

Mi Hwa Chung, MD, PhD : mhchung20@ hallym.or.kr

Corresponding author: Jung Eun Kim

Department of Anesthesiology and Pain Medicine, Kangnam Sacred Heart Hospital, Hallym University College of Medicine, 1, Singil-ro, Yeongdeungpo-gu, Seoul, Republic of Korea

Tel: 82-2-829-5230

E-mail: geri200@gmail.com 


\section{INTRODUCTION}

2

3 Herpes zoster is caused by the reactivation of latent varicella zoster virus in the trigeminal

4 and dorsal root ganglion [1,2]. Its most frequent complication is postherpetic neuralgia (PHN),

5 which is neuropathic pain resulting from peripheral nerve damage caused by the varicella

6 zoster virus [3,4]. PHN can reduce one's quality of life due to severe physical, psychological,

7 social, and functional disturbances as consequences of chronic pain [5-8].

8 Despite the existence of many treatments, PHN remains difficult to manage and is 9 refractory to most treatment modalities $[9,10]$. PHN treatment largely focuses on 10 symptomatic control of pain through long-term use of pain-relieving drugs such as 11 anticonvulsants, tricyclic antidepressants, topical anesthetics, and opioid analgesics [11], which present a high risk of side effects in elderly PHN patients.

Neuropathic pain associated with herpes zoster results from inflammatory neural damage caused by virus reactivation [12], which destroys affected central and peripheral nerves and leads to inflammation and an immune response. This is proposed to involve two processes: sensitization and deafferentiation. Peripheral and central sensitization result from nerve damage-induced excitability of primary afferent neurons, inflammation, and nociceptor irritation, whereas deafferentation is caused by degeneration of nociceptive neurons and dorsal reorganization due to a declining number of c-fibers and the sprouting of $\mathrm{A} \beta$ fibers [13]. These mechanisms suggest that appropriate analgesic and anti-inflammatory therapy could relieve PHN symptoms.

Previous studies report the effectiveness of epidural injection of local anesthetics and steroids in controlling neuropathic pain in herpes zoster patients [14-17]. Epidural anesthetics 
1 delivered to the distal portion of the spinal cord block central sensitization and provide pain

2 relief, whereas epidural steroids reduce inflammatory responses at the injured dorsal root

3 ganglion, spinal cord, and surrounding peripheral tissue. However, few studies have

4 examined the effectiveness and safety of epidural steroid administration in PHN patients.

5 In this randomized controlled trial, we evaluated the efficacy and safety of continuous

6 epidural infusion of local anesthetics with a one-time bolus of dexamethasone versus

7 dexamethasone pulse therapy among PHN patients.

8

9 MATERIALS AND METHODS

Participants

The study protocol was approved by institutional review board of Hallym University Kangnam Sacred Heart Hospital (reference number 2019-04-011) and registered at ClinicalTrials.gov (NCT03995563, Principal investigator: J.E.K). All participants received explanations of the study and provided written informed consent before enrollment. We included patients between 30 and 180 days after zoster onset who were admitted to the pain clinic center for PHN-related pain rated $\geq 7$ on a visual analog scale (VAS), with 0 representing "no pain" and 10 representing "the worst pain imaginable". Trigeminal nerveinvolved zoster patients or patients who had previously received epidural block treatment were excluded. We also excluded patients with hemostatic disorder or who were on antiplatelet therapy.

Patients were randomly assigned into two groups: 21 patients in group A were treated 
1 bolus, and 21 patients in group B were treated with continuous epidural infusion of local

2 anesthetics with dexamethasone pulse therapy.

\section{$3 \quad$ Procedure}

4 All patients were given $1 \mathrm{~g}$ cefazolin intravenously prior to the procedure and assumed a 5 prone position on the procedure table. Under fluoroscopic guidance, an 18-gauge Tuohy 6 needle was advanced into the epidural space at the second or third vertebral level below the 7 target level, and its proper positioning was confirmed using the loss of resistance technique. A 8 20-gauge epidural catheter was then inserted through the Tuohy needle into the epidural 9 space of the affected spinal nerve, and its placement was confirmed using contrast medium. 10 Patients received a bolus of $8 \mathrm{ml}$ of $0.19 \%$ ropivacaine and $5 \mathrm{mg}$ dexamethasone, and the catheter was fixed with subcutaneous tunneling to minimize infection risk.

After catheter placement, all patients received $0.095 \%$ ropivacaine infused at rate of 7 $\mathrm{ml} /$ hour for 10 days. Patients in group B received two additional 2.5-mg doses of dexamethasone via epidural catheter every 5 days over the 10 -day period and a final 5-mg epidural block 2 weeks after the epidural catheter was removed.

VAS scores were compared within and between groups before and 1, 2, 3, 4, 5, and 6 months after treatment. Response to treatment was defined as a $\geq 50 \%$ reduction in pain severity compared with that before the treatment or complete remission. Patients in complete remission were those who had a VAS score $\leq 2$ for more than three successive visits, subsided allodynia and hyperalgesia, and no longer needed medical support.

\section{Statistical analysis}

The normality of demographic data was evaluated using Kolmogorov-Smirnov tests.

Continuous variables are reported as mean \pm standard deviation and were analyzed using 
1 independent t-tests. Categorical variables are reported as frequency and percentage and were

2 analyzed using Chi-square or Fisher's exact tests. Logistic regression models were used to

3 evaluate the odds of $\mathrm{a} \geq 50 \%$ reduction in the severity of pain or complete remission of $\mathrm{PHN}$

4 within 6 months of treatment. Based on pilot study data, sample size determination was

5 performed with $\mathrm{G} *$ Power software (version 3.0.10) using a $\mathrm{z}$ test with a p1 proportion of 0.9,

$6 \mathrm{p} 2$ proportion of 0.5 , error probability of 0.05 , and power of 0.8 . Based on these parameters,

7 we determined that at least 20 patients were required in each group and thus enrolled 21

8 patients per group to account for drop-out. Data analysis was performed using SPSS (version

9 23, IBM Corp., Armonk, NY, USA) or SAS (version 9.4, SAS Inc., Cary, NC, USA), and P-

10 values of $<0.05$ were considered statistically significant.

RESULTS

A total of 42 patients were enrolled, with 21 randomized to each group. Age, sex, presence of underlying disease, level of involved dermatome, time to receive epidural block treatment, and pre-treatment VAS score were similar between patients in groups A and B (Table 1).

Patients in both groups showed significantly lower VAS scores after treatment compared with pre-treatment. However, patients in group B (dexamethasone pulse therapy) showed significantly lower VAS scores than patients in group A (one-time bolus dexamethasone) after treatment (Figure 1). Although patients in groups $\mathrm{A}$ and $\mathrm{B}$ had a similar likelihood of achieving a $\geq 50 \%$ reduction in pain severity after treatment, patients in group $\mathrm{B}$ were significantly more likely to achieve complete remission than patients in group A (Table 2). 


\section{Total}

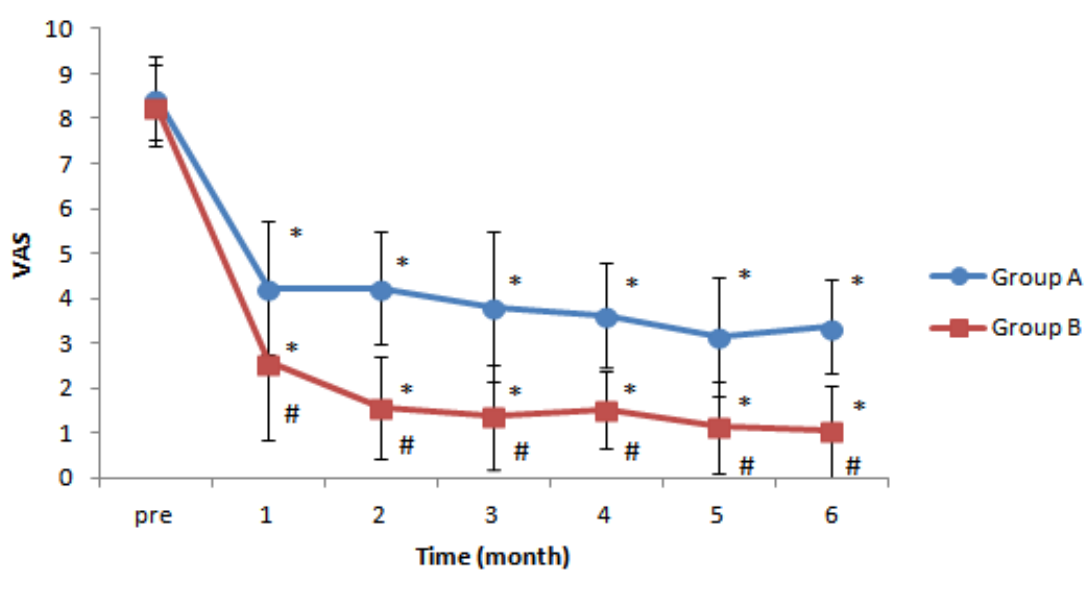

2 Figure 1. Changes in VAS score over time. Patients in both groups showed significant 3 reductions in VAS scores after treatment compared with pre-treatment, but patients in group

4 B (dexamethasone pulse therapy) showed significantly lower VAS scores than patients in 5 group A (one-time bolus of dexamethasone). $* \mathrm{P}<0.05$ compared with pre-treatment VAS 6 score. \#P $<0.05$ compared with group A.

7

8

9 
1 Table 1. Patient characteristics. SD, standard deviation.

2

\begin{tabular}{|c|c|c|c|}
\hline & Group A (n=21) & Group B (n=21) & P-value \\
\hline Age (years), mean \pm SD & $64.667 \pm 13.055$ & $67.429 \pm 9.852$ & 0.4436 \\
\hline Sex, $\mathrm{n}(\%)$ & & & 0.3456 \\
\hline Male & $7(33.3)$ & $10(47.6)$ & \\
\hline Female & $14(66.7)$ & $11(52.4)$ & \\
\hline $\begin{array}{c}\text { Presence of underlying disease, } \mathrm{n}(\%) \\
\text { None }\end{array}$ & $9(42.9)$ & $9(42.9)$ & $>0.9999$ \\
\hline $\begin{array}{c}\text { Hypertension, diabetes mellitus, or } \\
\text { chronic obstructive pulmonary disease }\end{array}$ & $12(57.1)$ & $12(57.1)$ & \\
\hline $\begin{array}{c}\text { Level of involved dermatome, } \mathrm{n}(\%) \\
\text { Cervical }\end{array}$ & $1(4.8)$ & $2(9.5)$ & \\
\hline Thoracic & $16(76.2)$ & $17(40.5)$ & \\
\hline Lumbar & $4(9.5)$ & $2(4.8)$ & \\
\hline (weeks), mean \pm SD & $10.952 \pm 7.290$ & $10.143 \pm 5.868$ & \\
\hline & & & \\
\hline & & & \\
\hline
\end{tabular}


1 Table 2. Between-group comparisons of reduction in pain severity and complete remission. OR, odds ratio; CI, confidence interval.

\begin{tabular}{|c|c|c|c|c|c|c|c|c|}
\hline & \multicolumn{3}{|c|}{ Reduction in pain severity } & \multicolumn{3}{c|}{ Complete remission } \\
\hline & $\begin{array}{c}\geq 50 \% \text { reduction } \\
\text { in pain severity }\end{array}$ & $\begin{array}{c}<50 \% \text { reduction } \\
\text { in pain severity }\end{array}$ & OR (95\% CI) & P-value & VAS score $\leq 2$ & VAS score $>2$ & OR (95\% CI) & P-value \\
at terminal visit & at terminal visit & & \\
\hline $\begin{array}{c}\text { Group A, } \mathrm{n} \\
(\%)\end{array}$ & $16(76.19)$ & $5(23.81)$ & Reference & & $6(28.57)$ & $15(71.43)$ & Reference & \\
\hline $\begin{array}{c}\text { Group B, } \mathrm{n} \\
(\%)\end{array}$ & $20(95.24)$ & $1(4.76)$ & $\begin{array}{c}6.25(0.662- \\
59.027)\end{array}$ & 0.1097 & $17(80.95)$ & $4(19.05)$ & $\begin{array}{c}10.625(2.509- \\
44.984)\end{array}$ & 0.0013 \\
\hline
\end{tabular}

2 


\section{DISCUSSION}

2

3 Our results show that among PHN patients, continuous epidural infusion of local anesthetics

with dexamethasone pulse therapy resulted in a greater reduction in pain and likelihood of complete remission than continuous epidural infusion of local anesthetics with a one-time bolus of dexamethasone. Furthermore, continuous epidural infusion of local anesthetics with dexamethasone pulse therapy alleviated PHN-related allodynia and hyperalgesia without causing adverse effects. We speculate that dexamethasone interrupts neurogenic inflammation and promotes recovery of neural damage in PHN patients, with more frequent and higher doses exerting better effects. Thus, continuous epidural blockade of nociceptive input paired with intense anti-inflammatory therapy may be an effective treatment modality for PHN.

Although the pathogenesis of PHN is not fully understood, herpes zoster is known to affect the central and peripheral nervous systems, resulting in PHN $[18,19]$. PHN-related neuropathic pain is caused by inflammatory neural damage caused by the varicella zoster virus [20]. Two mechanisms of PHN have been proposed: sensitization and deafferentation $[21,22]$. Sensitization is caused by the loss of $\gamma$-aminobutyric acid inhibitory neurons in the dorsal root ganglion after nerve injury and a decreased nociceptor threshold induced by inflammatory mediators such as substance P, histamines, and cytokines [23,24]. This sensitization causes spontaneous pain, allodynia, and hyperalgesia. Deafferentation is caused by dorsal reorganization, which occurs due to a decline in the number of c-fibers and the sprouting of $\mathrm{A} \beta$ fibers $[21,23]$, which rewire in the dorsal root ganglion and connect with the pain-transmitting spinothalamic tract, thereby producing allodynia and paresthesia. These mechanisms suggest that proper analgesic and anti-inflammatory therapy could relieve the 
1 symptoms of PHN.

2 Continuous epidural infusion of local anesthetics blocks nociceptive input at the distal

3 portion of the spinal cord (i.e., dorsal root ganglion, spinal nerve roots, peripheral regions of 4 the spinal cord), thus providing analgesia and interrupting sensitization [25-28]. By contrast, 5 dexamethasone is a strong anti-inflammatory agent that reduces deafferentation by inhibiting 6 inflammation and concomitant swelling-induced ischemic nerve damage and promotes nerve 7 tissue repair by reducing edema and cytotoxic responses [29-31]. Dexamethasone also exerts 8 a direct membrane action that prevents ectopic discharges from c-fibers, blocking the 9 transmission of nociceptive input and thereby providing analgesia [32-34].

Histopathological studies of PHN patients suggest that inflammatory processes are involved in the development of PHN. In a postmortem study, Watson et al. reports that infiltration and accumulation of immune cells were found around the spinal cord and spinal nerve of PHN patients [35]. This inflammatory component of PHN suggests that antiinflammatory treatment could help reverse or at least limit its progression. Previous studies show that intrathecal methylprednisolone relieves PHN-related pain and allodynia $[10,36][37,38]$. In these studies, patients receiving intrathecal methylprednisolone showed reduced cerebrospinal fluid concentrations of interleukin- 8 , indicating that this treatment reduces pain and allodynia by decreasing an ongoing inflammatory reaction. However, this procedure caused serious complications, including chemical or aseptic meningitis, transverse myelitis, lumbar radiculitis, cauda equina syndrome, intractable headache, urinary retention, and chronic arachnoiditis [39,40]. Currently, methylprednisolone is not approved for intrathecal administration due to its severe adverse effects, including arachnoiditis [41]. 
1 epidural route, instead of an intrathecal route, in PHN patients. This procedure reduced VAS

2 scores in all 42 PHN patients without complications. Furthermore, dexamethasone pulse

3 therapy was more effective in alleviating PHN-related pain, allodynia, and hyperalgesia than

4 a one-time bolus of dexamethasone. These results suggest that epidural dexamethasone pulse

5 therapy is an effective treatment for PHN and is safer than intrathecal methylprednisolone

6 administration.

7 Although continuous epidural infusion of local anesthetics with dexamethasone pulse

8 therapy significantly reduced VAS scores and increased the likelihood of complete remission

9 compared with a one-time bolus of dexamethasone, the number of patients who experienced a

$10 \geq 50 \%$ reduction in pain severity did not significantly differ between groups, likely because

both procedures were effective treatments for PHN. The absence of a control group that did not receive epidural steroids is a limitation of this study; however, not treating PHN patients

with epidural steroids was not an option due to ethical concerns. Another limitation is that we enrolled PHN patients 30-180 days after zoster onset and therefore did not include patients with "well established" PHN, who are not likely to experience reductions in pain or achieve complete remission [42]. However, we are currently investigating treatment effects over time in other prospective trials with large sample sizes. Another limitation is that continuous epidural infusion of local anesthetics with dexamethasone pulse therapy is costly. However, severe PHN pain can impair quality of life by causing physical disability and emotional distress and thus impose its own economic burden on PHN patients and society.

In conclusion, our results suggest that continuous epidural infusion of local anesthetics with dexamethasone pulse therapy results in greater alleviation of PHN-related pain, allodynia, and hyperalgesia than continuous epidural infusion of local anesthetics with a one- 
1 time bolus of dexamethasone without causing any adverse effects. Therefore, continuous

2 epidural blockade of nociceptive input with intense anti-inflammatory therapy appears to be a

3 safe and effective treatment modality for PHN.

4

\section{Acknowledgements}

6 The authors thank all the participants. None of the authors of the manuscript received any 7 remuneration.

8

9 Conflicts of Interest: The authors declare no conflict of interest. 


\section{REFERENCES}

2 1. Hillebrand, K.; Bricout, H.; Schulze-Rath, R.; Schink, T.; Garbe, E. Incidence of 3 herpes zoster and its complications in germany, 2005-2009. J Infect 2015, 70, 178-186.

$4 \quad 2 . \quad$ Kim, Y.J.; Lee, C.N.; Lim, C.Y.; Jeon, W.S.; Park, Y.M. Population-based study of the epidemiology of herpes zoster in korea. J Korean Med Sci 2014, 29, 1706-1710.

63 Gershon, A.A. Epidemiology and management of postherpetic neuralgia. Semin Dermatol 1996, 15, 8-13.

4. Dworkin, R.H.; Gnann, J.W., Jr.; Oaklander, A.L.; Raja, S.N.; Schmader, K.E.; Whitley, R.J. Diagnosis and assessment of pain associated with herpes zoster and postherpetic neuralgia. J Pain 2008, 9, S37-44.

5. Katz, J.; Cooper, E.M.; Walther, R.R.; Sweeney, E.W.; Dworkin, R.H. Acute pain in herpes zoster and its impact on health-related quality of life. Clin Infect Dis 2004, 39,

6. Gater, A.; Abetz-Webb, L.; Carroll, S.; Mannan, A.; Serpell, M.; Johnson, R. Burden of herpes zoster in the uk: Findings from the zoster quality of life (zqol) study. BMC Infect Dis 2014, 14, 402.

7. Johnson, R.W.; Bouhassira, D.; Kassianos, G.; Leplege, A.; Schmader, K.E.; Weinke, T. The impact of herpes zoster and post-herpetic neuralgia on quality-of-life. $B M C$

8. Serpell, M.; Gater, A.; Carroll, S.; Abetz-Webb, L.; Mannan, A.; Johnson, R. Burden of post-herpetic neuralgia in a sample of uk residents aged 50 years or older: Findings from the zoster quality of life (zqol) study. Health Qual Life Outcomes 2014, 12, 92. 
$1 \quad$ consecutive cases. Pain 1985, 23, 381-386.

2 10. Lin, C.S.; Lin, Y.C.; Lao, H.C.; Chen, C.C. Interventional treatments for postherpetic neuralgia: A systematic review. Pain Physician 2019, 22, 209-228.

4 11. Johnson, R.W.; McElhaney, J. Postherpetic neuralgia in the elderly. Int J Clin Pract 5 2009, 63, 1386-1391.

6 12. Kim, H.; Choi, Y.L.; Lee, D.K.; Choi, S.S.; Lee, I.O.; Kong, M.H.; Kim, N.S.; Lim, S.H.; Lee, M. The neurological safety of intrathecal acyclovir in rats. Pain Physician 2012, 15, E107-113.

13. Woolf, C.J.; Mannion, R.J. Neuropathic pain: Aetiology, symptoms, mechanisms, and management. Lancet 1999, 353, 1959-1964.

14. Opstelten, W.; Van Wijck, A.J.; Van Essen, G.A.; Buskens, E.; Bak, A.A.; Kalkman, C.J.; Verheij, T.J.; Moons, K.G. The pine study: Rationale and design of a randomised comparison of epidural injection of local anaesthetics and steroids versus care-asusual to prevent postherpetic neuralgia in the elderly [isrctn32866390]. BMC Anesthesiol 2004, 4, 2.

15. van Wijck, A.J.; Opstelten, W.; Moons, K.G.; van Essen, G.A.; Stolker, R.J.; Kalkman, C.J.; Verheij, T.J. The pine study of epidural steroids and local anaesthetics to prevent postherpetic neuralgia: A randomised controlled trial. Lancet 2006, 367, 219-224.

16. Pasqualucci, A.; Pasqualucci, V.; Galla, F.; De Angelis, V.; Marzocchi, V.; Colussi, R.; Paoletti, F.; Girardis, M.; Lugano, M.; Del Sindaco, F. Prevention of post-herpetic neuralgia: Acyclovir and prednisolone versus epidural local anesthetic and methylprednisolone. Acta Anaesthesiol Scand 2000, 44, 910-918.

17. Seo, Y.G.; Kim, S.H.; Choi, S.S.; Lee, M.K.; Lee, C.H.; Kim, J.E. Effectiveness of 
continuous epidural analgesia on acute herpes zoster and postherpetic neuralgia: A retrospective study. Medicine (Baltimore) 2018, 97, e9837.

18. Nurmikko, T.; Wells, C.; Bowsher, D. Pain and allodynia in postherpetic neuralgia: Role of somatic and sympathetic nervous systems. Acta Neurol Scand 1991, 84, 146152.

19. Kim, E.D.; Lee, Y.I.; Park, H.J. Comparison of efficacy of continuous epidural block and pulsed radiofrequency to the dorsal root ganglion for management of pain persisting beyond the acute phase of herpes zoster. PLoS One 2017, 12, e0183559.

20. Johnson, R.W.; Rice, A.S. Clinical practice. Postherpetic neuralgia. N Engl J Med 2014, 371, 1526-1533.

21. Baron, R. Mechanisms of postherpetic neuralgia--we are hot on the scent. Pain 2008, $140,395-396$.

22. Johnson, R.W. Zoster-associated pain: What is known, who is at risk and how can it be managed? Herpes 2007, 14 Suppl 2, 30-34.

23. van Wijck, A.J.; Wallace, M.; Mekhail, N.; van Kleef, M. Evidence-based interventional pain medicine according to clinical diagnoses. 17. Herpes zoster and post-herpetic neuralgia. Pain Pract 2011, 11, 88-97.

24. Premkumar, L.S. Targeting trpv1 as an alternative approach to narcotic analgesics to treat chronic pain conditions. AAPS J 2010, 12, 361-370.

25. Manabe, H.; Dan, K.; Higa, K. Continuous epidural infusion of local anesthetics and shorter duration of acute zoster-associated pain. Clin J Pain 1995, 11, 220-228.

26. Hwang, S.M.; Kang, Y.C.; Lee, Y.B.; Yoon, K.B.; Ahn, S.K.; Choi, E.H. The effects of epidural blockade on the acute pain in herpes zoster. Arch Dermatol 1999, 135, 1359- 
1364.

27. Riopelle, J.M.; Naraghi, M.; Grush, K.P. Chronic neuralgia incidence following local anesthetic therapy for herpes zoster. Arch Dermatol 1984, 120, 747-750.

28. Manabe, H.; Dan, K.; Hirata, K.; Hori, K.; Shono, S.; Tateshi, S.; Ishino, H.; Higa, K. Optimum pain relief with continuous epidural infusion of local anesthetics shortens the duration of zoster-associated pain. Clin J Pain 2004, 20, 302-308.

29. Hall, E.D. Glucocorticoid effects on central nervous excitability and synaptic transmission. Int Rev Neurobiol 1982, 23, 165-195.

30. Forrest, J.B. The response to epidural steroid injections in chronic dorsal root pain. Can Anaesth Soc J 1980, 27, 40-46.

31. Marshall, L.L.; Trethewie, E.R.; Curtain, C.C. Chemical radiculitis. A clinical, physiological and immunological study. Clin Orthop Relat Res 1977, 61-67.

32. Devor, M.; Govrin-Lippmann, R.; Raber, P. Corticosteroids suppress ectopic neural discharge originating in experimental neuromas. Pain 1985, 22, 127-137.

33. Eaglstein, W.H.; Katz, R.; Brown, J.A. The effects of early corticosteroid therapy on the skin eruption and pain of herpes zoster. JAMA 1970, 211, 1681-1683.

34. Forrest, J.B. Management of chronic dorsal root pain with epidural steroid. Can Anaesth Soc J 1978, 25, 218-225.

35. Watson, C.P.; Deck, J.H.; Morshead, C.; Van der Kooy, D.; Evans, R.J. Post-herpetic neuralgia: Further post-mortem studies of cases with and without pain. Pain 1991, 44, $105-117$.

36. Kumar, V.; Krone, K.; Mathieu, A. Neuraxial and sympathetic blocks in herpes zoster and postherpetic neuralgia: An appraisal of current evidence. Reg Anesth Pain Med 
1

2004, 29, 454-461.

37. Kotani, N.; Kushikata, T.; Hashimoto, H.; Kimura, F.; Muraoka, M.; Yodono, M.; Asai, M.; Matsuki, A. Intrathecal methylprednisolone for intractable postherpetic neuralgia. N Engl J Med 2000, 343, 1514-1519.

38. Kikuchi, A.; Kotani, N.; Sato, T.; Takamura, K.; Sakai, I.; Matsuki, A. Comparative therapeutic evaluation of intrathecal versus epidural methylprednisolone for long-term analgesia in patients with intractable postherpetic neuralgia. Reg Anesth Pain Med 1999, 24, 287-293.

39. Nelson, D.A.; Landau, W.M. Intrathecal methylprednisolone for postherpetic neuralgia. N Engl J Med 2001, 344, 1019; author reply 1021-1012.

40. Nelson, D.A.; Landau, W.M. Intrathecal steroid therapy for postherpetic neuralgia: A review. Expert Rev Neurother 2002, 2, 631-637.

41. Dubinsky, R.M.; Kabbani, H.; El-Chami, Z.; Boutwell, C.; Ali, H.; Quality Standards Subcommittee of the American Academy of, N. Practice parameter: Treatment of postherpetic neuralgia: An evidence-based report of the quality standards subcommittee of the american academy of neurology. Neurology 2004, 63, 959-965.

42. Fishman SM, Ballantyne JC, Rathmell JP. Bonica's Management of Pain 4th edition. Lippincott Williams \& Wilkins, Philadelphia, 2010. 